\title{
Broad Spectrum $\beta$-lactamase Inhibition By A Thioether Substituted Bicyclic Boronate
}

Anete Parkova*, Anka Lucic ${ }^{\star *}$, Alen Krajnc**, Jürgen Brem*, Karina Calvopiña**, Gareth W. Langley $^{\star \star_{*}}$, Michael A. McDonough ${ }^{\star *}$, Peteris Trapencieris*, and Christopher J. Schofield ${ }^{\star *}$.

*Latvian Institute of Organic Synthesis, Aizkraukles 21, LV-1006, Riga, Latvia; ${ }^{* *}$ The Chemistry Research Laboratory, The Department of Chemistry, 12 Mansfield Road, Oxford OX1 3TA United Kingdom.

+Current Address: Charles River Laboratories, Chesterford Research Park, Saffron Walden, Essex, CB10 1XL.

Correspondence should be addressed to: CJS (christopher.schofield@chem.ox.ac.uk) or PT (peteris@osi.lv).

$\beta$-Lactamases comprise the most widely used mode of resistance to $\beta$-lactam antibiotics. Cyclic boronates have shown promise as a new class of $\beta$-lactamase inhibitor, with pioneering potential to potently inhibit both metallo- and serine- $\beta$-lactamases. We report studies concerning a bicyclic boronate ester with a thioether rather than the more typical $\beta$ lactam antibiotic 'C-6/C-7' acylamino type sidechain which is present in the penicillin/cephalosporin antibiotics. The thioether bicyclic boronate ester was tested for activity against representative serine- and metallo- $\beta$-lactamases. The results support the broad inhibition potential of bicyclic boronate based inhibitors with different side chains, including against metallo- $\beta$-lactamases from B1, B2 and B3 subclasses. Combined with previous crystallographic studies, analysis of a crystal structure of the thioether inhibitor with 
the clinically relevant VIM-2 metallo $\beta$-lactamase implies that further SAR work will expand the already broad scope of $\beta$-lactamase inhibition by bicyclic boronates.

Keywords: $\beta$-lactam antibiotic resistance; boronate/boron based $\beta$-lactamase/hydrolase inhibitors; serine $\beta$-lactamase, metallo $\beta$-lactamase, carbapenem/penicillin/cephalosporin.

The $\beta$-lactams are the most prescribed class of antibacterials, but their clinical utility is being eroded by multiple resistance mechanisms. ${ }^{1}$ Currently, the most prevalent resistance mechanism is hydrolysis via $\beta$-lactamases ${ }^{2}$ (Figure 1 ), of which there are two mechanistic groups - the nucleophilic serine- $\beta$-lactamases (Ambler Classes A, C, D; SBLs) and the zinc ion dependent metallo- $\beta$-lactamases (Class B, MBLs). ${ }^{3}$ Whilst for many years the SBLs were the most clinically relevant $\beta$-lactamases, the MBLs are of increasing relevance, being endemic in some regions. ${ }^{4,5}$ Several SBL inhibitors, including clavulanic acid, sulbactam and tazobactam (Figure 1), are established for clinical use in combination with $\beta$-lactam antibiotics. These combinations have been highly effective against Class $A$ and some Class D $\beta$-lactamases.$^{6-8}$ However, they are ineffective against MBLs and evolved broad spectrum SBLs. ${ }^{9}$ Moreover, recent studies have shown that MBLs are being expressed alongside SBLs, making these current methods even less effective. ${ }^{9}$

The development of avibactam, a broad spectrum SBL inhibitor, was significant as this was the first clinically used $\beta$-lactamase inhibitor which did not contain a $\beta$-lactam ring, reducing its rate of SBL cleavage. ${ }^{10}$ However, like the $\beta$-lactams, avibactam works by the formation of an acyl-enzyme type complex, which has the potential to be hydrolytically labile. ${ }^{11}$ Further, there is evidence that avibactam may become susceptible to MBLs. ${ }^{12}$ Consequently, there is a desire to develop $\beta$-lactamase inhibitors and antibiotics targeting the transpeptidase targets of the $\beta$-lactams that do not operate via an acylation type mechanism susceptible to $\beta$-lactamases. 
Towards this objective, the "transition state" analogue approach for SBL/transpeptidase inhibition has long been explored. ${ }^{11,13-15}$ Of the different functional groups investigated for this approach, cyclic boronic acids/boronate esters have emerged as of particular promise (Figure 1)..$^{13,14}$ One such compound, vaborbactam ${ }^{16}(\mathbf{1})$, has been approved for clinical use as an SBL inhibitor, but it does not efficiently inhibit MBLs and has limited SBL coverage. ${ }^{16}$ By contrast, bicyclic boronates (e.g. 2 and VNRX-5133) are reported to inhibit a broader range of SBLs ${ }^{14,17-19}$ as well as some members of the clinically important B1 MBL subfamily such as VIM-2. ${ }^{18-20}$

There are only very limited SAR studies reported on potent bicyclic boronates as $\beta$ lactamase inhibitors, with work to date focusing on those with the canonical penicillin/cephalosporin type acylamino side chains on the boronate ester ring. ${ }^{14,17,20}$ Here, we report biochemical and biophysical studies on a bicyclic boronate (3) (reported in the patent literature ${ }^{21}$ ) which has a thioether side chain positioned analogously to the typical C6/C-7 side chain of penicillins/cephalosporins (Figure 1). The results further validate the potential of bicyclic boronates as broad-spectrum inhibitors of both SBLs and MBLs, and highlight the need for more SAR work on side chain variants of bicyclic boronate $\beta$ lactamase inhibitors. 
A
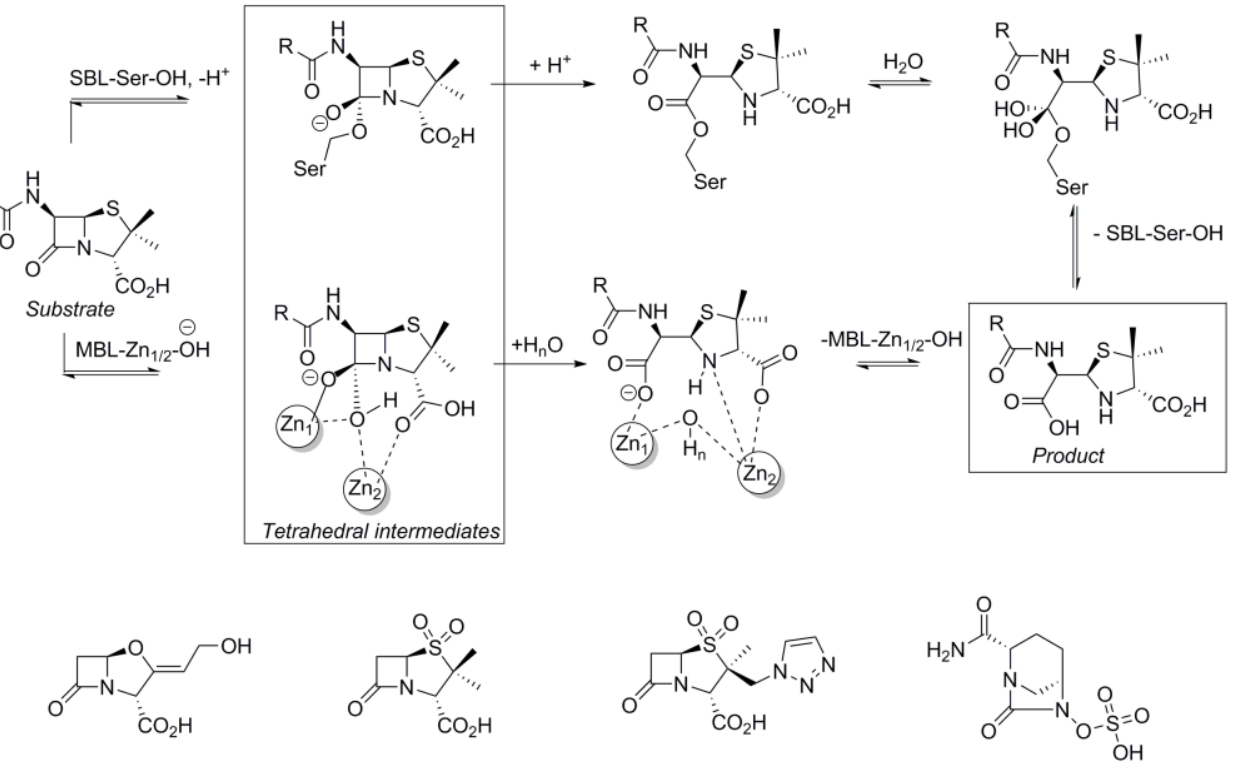

clavulanic acid

sulbactam

tazobactam

avibactam

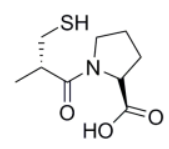

L-captopril

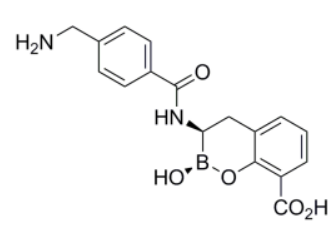

2 (sp $\left.\mathrm{sporm}^{2}\right)$

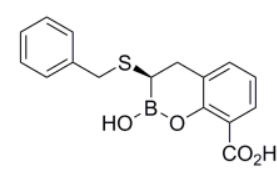

$3(R)$

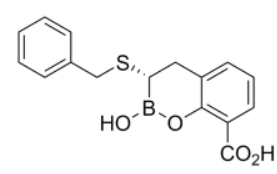

$3(S)$<smiles>NCCNC1CCC(CC(=O)NC2Cc3cccc(C(=O)O)c3OP2O)CC1</smiles>

VNRX 5133 (Taniborbactam) sp ${ }^{2}$ form

Figure $1 \beta$-lactamase mechanisms and inhibitors. A) Outline of the $S B L$ and $M B L$ mechanisms with a penicillin substrate. (B) Clinically used SBL inhibitors (clavulanate, sulbactam, tazobactam, avibactam) which operate using acylation type mechanisms and Lcaptopril, a non-clinically used MBL inhibitor. (C) Boronate based $\beta$-lactamase inhibitors the SBL inhibitor vaborbactam and the broader spectrum bicyclic boronates 2, VNRX-5133 and 3, the latter of which is the subject of the current work. Note that both the penicillins and 2 have an acylamino side chain. 


\section{Results}

\section{Synthesis of thioether substituted cyclic boronate 3}

The thioether substituted cyclic boronate $\mathbf{3}$ was prepared via an eight-step stereoselective route from commercially available 3-methylsalicylic acid (Figure 2). One-pot protection of the phenolic alcohol and benzoic acid groups under acidic conditions gave acetonide 4 (71\%), which was then brominated using $N$-bromosuccinimide to give benzylic bromide 5 (72\%). Bromide 5 underwent Miyaura borylation to give pinacolato boronate 6, which was transesterified in situ with $(1 S, 2 S, 3 R, 5 S)-(+)$-pinanediol to give the boronic acid (+)pinanediol ester $\mathbf{7}$ in good yield (87\% over two steps). Boronate $\mathbf{7}$ was then subjected to Matteson homologation ${ }^{22,23}$ to give the chloride 8 as a mixture of stereoisomers $(8 S: 8 R$ 72:28, respectively, as assigned by $\left.{ }^{1} \mathrm{H} N M R\right)^{24}$. Subsequent nucleophilic substitution (with assumed inversion) with benzylmercaptan gave thioether $9(70 \%)$ with inversion of stereochemistry (8S:8R 24:76, as assigned by $\left.{ }^{1} \mathrm{H} N M R\right)$. Cleavage of the isopropylidene protecting group and hydrolysis of the chiral auxiliary gave the desired bicyclic boronate $\mathbf{3}$, which was isolated as a mixture of $(R / S)$-enantiomers.

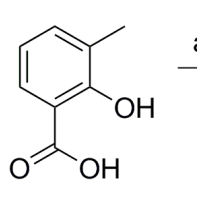<smiles>Cc1cccc2c1OC(C)(C)OC2=O</smiles>

4

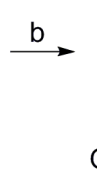<smiles>[B]Cc1cccc2c1OC(C)(C)OC2=O</smiles>

5

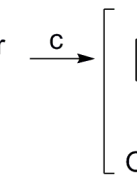<smiles>CC1(C)Oc2cccc(CB3OC(C)(C)C(C)(C)O3)c2O1</smiles>

6

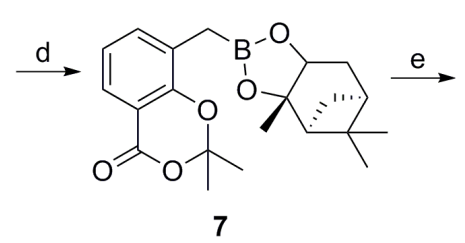

7

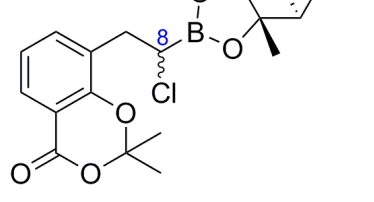

$8(8 S: 8 R, 72: 28)$

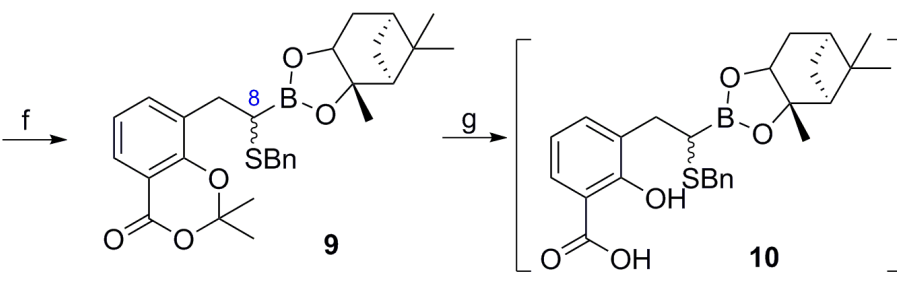

$9(8 S: 8 R, 24: 76)$<smiles>O=C(O)c1cccc2c1OB(O)CC2SCc1ccccc1</smiles>

(R)-3 major<smiles>O=C(O)c1cccc2c1OB(O)C(SCc1ccccc1)C2</smiles>

(S)-3

Figure 2. Synthesis of C-2 substituted bicyclic boronates. (a) Trifluoroacetic acid, trifluoroacetic anhydride, acetone, $0^{\circ} \mathrm{C}$ then room temp. (71\%); (b) $\mathrm{N}$-bromosuccinimide, benzoyl peroxide, $\mathrm{MeCN}, 90^{\circ} \mathrm{C}(72 \%)$; (c) bis(pinacolato)diboron, $\mathrm{Pd}(\mathrm{dppf}) \mathrm{Cl}_{2}, \mathrm{KOAc}$, dioxane, $90^{\circ} \mathrm{C}$; (d) $(1 S, 2 S, 3 R, 5 S)-(+)$-pinanediol, THF, $30^{\circ} \mathrm{C}$ (87\% over two steps); (e) 
$\mathrm{CH}_{2} \mathrm{Cl}_{2}, n$-BuLi, $\mathrm{ZnCl}_{2}$, THF, $-100^{\circ} \mathrm{C}$, then room temp. (61\%); (f) $\mathrm{PhCH}_{2} \mathrm{SH}, \mathrm{Et}_{3} \mathrm{~N}, \mathrm{CH}_{2} \mathrm{Cl}_{2}$, room temp. (70\%); (g) aqueous $\mathrm{KOH}, \mathrm{THF}, 60^{\circ} \mathrm{C}$; (h) $\mathrm{cHCl}, \mathrm{BuB}(\mathrm{OH})_{2}, \mathrm{MeCN}, \mathrm{H}_{2} \mathrm{O}, 40^{\circ} \mathrm{C}$ (31\%). dppf = 1,1'-bis(diphenylphosphino)ferrocene, $\mathrm{Bn}=$ benzyl.

\section{Inhibition of $\beta$-lactamases}

3 was tested for inhibition against ten $\beta$-lactamases, comprising representatives from all four Ambler classes, using an established fluorescence based method. ${ }^{14,17,20,25,26}$ The clinically used SBL inhibitor, avibactam ${ }^{11}$, and L-captopril, a well-studied and moderately potent MBL inhibitor (Figure 1) ${ }^{27}$, were used for comparison. As anticipated, avibactam did not manifest MBL inhibition ${ }^{11}$ and L-captopril did not manifest SBL inhibition. ${ }^{27}$ By contrast thioether 3, inhibited all 10 of the tested $\beta$-lactamases, though like the reported acylamino bicyclic boronates (e.g. $2^{14,20}$ and VNRX-5133 ${ }^{18,19}$ ), showed variations in potency. Notably, the inhibition profiles for $\mathbf{2}$, VNRX-5133 and 3 differ (Table 1). With the class A and C SBLs, 3 and VNRX-5133 are less potent than 2 against the A TEM-116 enzyme, but $\mathbf{3}$ is more potent than 2 and VNRX-5133 against the AmpC enzyme from $P$. aeruginosa.

The results for the inhibition of the class D enzymes OXA-10 and OXA-48 by 3 are notable. Class $D$ enzymes require a lysine carbamate for catalysis, which is formed by reaction of an essential active site lysine with (bi)carbonate / carbon dioxide ${ }^{28-30}$ (hence OXA assays were carried out with and without added bicarbonate). Notably, 3, like cyclic boronate 2 and VNRX-5133, was not highly potent against the Class D enzyme OXA-10, either with or without added bicarbonate $(100 \mathrm{mM})$, and the $\mathrm{plC}_{50}$ value was reduced in the latter case $\left(\mathrm{plC}_{50}\right.$ from 5.9 to 4.1 ; Table 1$)$. Importantly, thioether 3 was significantly more potent than 2 and VNRX-5133 ${ }^{18,19}$ (or avibactam) against OXA-48, an SBL of major contemporary clinical importance ${ }^{10-12}$. The $\mathrm{plC}_{50}$ values of 3 against OXA-48 both in the absence and presence of bicarbonate were both substantially greater than for 2 and VNRX-5133(Table 1). ${ }^{30}$ Recent work employing kinetic and biophysical (NMR and crystallography) analyses shows that 
different inhibitor classes interact with Class D OXA-enzymes in a manner that differently influences their lysine-carbamylation status. ${ }^{28}$ The molecular basis of the difference in potency between 3 and 2 for OXA-10 and OXA-48 merits further investigation and will be the subject of future studies.

Most importantly, thioether 3 inhibits a range of MBLs supporting the proposal that bicyclic boronates have considerable potential as potent broad spectrum SBL and $\mathrm{MBL}$ inhibitors. ${ }^{14,20}$ In terms of the tested B1 MBLs (NDM-1, VIM-1, VIM-2), 3 was considerably more potent than L-captopril, by at least ten-fold. 3 was of similar (NDM-1, VIM-1) ,or reduced (VIM-2) potency compared to 2 against B1 MBLs. These differences in potency likely reflect variations in the active sites of individual MBLs, e.g. VIM-1 and VIM-2 differ in their binding modes for the $\beta$-lactam substrate (or analogous inhibitor) carboxylate (Figure 3). ${ }^{31}$ The increased potency of 3 compared to 2 , versus the B3 MBL L $1^{14}$ and a mono zinc B2 MBL (CphA) is notable because it implies further structure active relationship (SAR) studies will likely expand the scope of potent inhibition by bicyclic boronates to all three MBL subclasses. 


\begin{tabular}{|c|c|c|c|c|c|c|}
\hline $\mathrm{plC}_{50} \mathrm{Va}$ & & & & & & \\
\hline $\begin{array}{l}\text { Ambler } \\
\text { Class }\end{array}$ & $\beta$-Lactamase & Avibactam plC $\mathrm{p}_{50}$ & $\begin{array}{l}\text { L-Captopril } \\
\mathrm{plC}_{50}\end{array}$ & $3 \mathrm{plC}_{50}$ & $2 \mathrm{plC}_{50}$ & $\begin{array}{l}\text { VNRX-5133 } \\
\text { pIC }_{50}{ }^{18,19}\end{array}$ \\
\hline A & TEM-116 & 8.1 & $<3.4$ & 6.7 & $8.5^{20}$ & $6.92^{18}$ \\
\hline B1 & IMP-1 & $<3.4$ & 5.0 & 6.9 & $6\left(5^{20}\right)$ & $5.6^{18}$ \\
\hline B1 & NDM-1 & $<3.4$ & 5.8 & 7.4 & $7.5^{20}$ & $8^{18}$ \\
\hline B1 & VIM-1 & $<3.4$ & 5.6 & 7.1 & $7.0^{14}$ & $8.1^{18}$ \\
\hline B1 & VIM-2 & $<3.4$ & 6.1 & 7.2 & $8.5^{20}$ & $9.3^{18}, 7.7^{19}$ \\
\hline B2 & CphA & $<2.4$ & $<5.0$ & 6.3 & $>4^{20}$ & $5.6^{18}$ \\
\hline B3 & $\overline{\mathrm{L} 1}$ & $<4.7$ & 5.6 & 5.3 & Not inhibited & $<5^{18}$ \\
\hline C & $\begin{array}{l}\text { AmpC } \\
\text { (P.aeruginosa) }\end{array}$ & 6.5 & $<4.4$ & 7.8 & $6.9^{14}$ & $6.5^{18}, 7.5^{19}$ \\
\hline $\mathrm{D}$ & OXA-10 & $<4.7$ & $<4.4$ & 5.9 & 4.5 & $6.6^{18}$ \\
\hline $\mathrm{D}$ & $\begin{array}{l}\text { OXA-10 } \\
(+100 \mathrm{mM} \\
\left.\mathrm{NaHCO}_{3}\right)\end{array}$ & $<4.7$ & $<4.4$ & 4.1 & $4.7\left(5.2^{20}\right)$ & $6.2^{18}$ \\
\hline $\mathrm{D}$ & OXA-48 & 6.2 & $<4.4$ & 8.2 & 4.6 & $6.3^{18}, 6.4^{19}$ \\
\hline $\mathrm{D}$ & $\begin{array}{l}\text { OXA-48 } \\
(+100 \mathrm{mM} \\
\left.\mathrm{NaHCO}_{3}\right)\end{array}$ & 6.1 & $<4.4$ & 8 & $4.8\left(5.6^{14}\right)$ & $5.6^{18}$ \\
\hline
\end{tabular}

Table 1. plC $_{50}$ values for 3 with several $\beta$-lactamases as well as plC $_{50}$ values for selected reported inhibitors. Inhibition assays for $\beta$-lactamases were performed as described. ${ }^{26}$ The cephalosporin FC-5 was used as a substrate for VIM-1, VIM-2, IMP-1, NDM-1, SPM-1, TEM-116, OXA-10, and OXA-48 ${ }^{20}$; meropenem was used for $\mathrm{Cph}^{19}$. Column 1 defines the Ambler class or subclass for MBLs of the $\beta$-lactamases used. Experiments involving inhibition of OXA-10 and OXA-48 by compound 2 were done with and without added bicarbonate. All in vitro assays except, for VNRX-5133, were freshly determined. The results are generally in accord with the reported values ${ }^{14,18-20}$, with exceptions in parentheses. 


\section{Minimum Inhibitory Concentrations}

We then investigated the potency of $\mathbf{3}$ in microbiological assays. Given the inhibitory activity of 3 against OXA-48, we assessed its ability to restore the antimicrobial activity of a carbapenem (meropenem) against an OXA-48 producing bacteria (Klebsiella pneumoniae NCTC 13442) and compared it with the monocyclic boronate, vaborbactam. Determination of MIC values were performed in triplicate using broth microdilution following CLSI (Clinical Laboratory Standards Institute) guidelines. ${ }^{32}$ Plates were incubated overnight at $37^{\circ} \mathrm{C}$ for $18-$ 24 hours and the absorbance at $600 \mathrm{~nm}$ was read using a ClarioSTAR (BMG LabTech) microplate reader.

Meropenem alone had an MIC value of $4 \mu \mathrm{g} \mathrm{mL}^{-1}$ against Klebsiella pneumoniae NCTC 13442. As expected, the addition of vaborbactam has no effect in an OXA-48 carrier ${ }^{33}$ with the MIC value being maintained at $4 \mu \mathrm{gL}^{-1}$. However, the combination of meropenem and 3 at the same fixed concentration used for vaborbactam $\left(8 \mu \mathrm{g} \mathrm{mL} \mathrm{m}^{-1}\right)$ reduced the MIC value to the susceptible range $\left(1 \mu \mathrm{g} \mathrm{mL} \mathrm{L}^{-1}\right)$. Although, 3 is not particularly potent in these microbiological assays, this observation provides further evidence to support the proposal that bicyclic boronates with varied side chains should be further explored to identify more potent broad spectrum $\beta$-lactamase inhibitors.

\section{Crystallographic investigations}

To investigate the mode of $\beta$-lactamase inhibition by $\mathbf{3}$, we obtained a crystal structure of VIM-2 in complex with 3. Crystals appeared in wells with a solution of $0.2 \mathrm{M} \mathrm{MgCl}_{2}, 0.1 \mathrm{M}$ Tris $\mathrm{pH} 8.25$ and 25\% PEG 8000; a structure of VIM-2 in complex with 3 was determined to $1.4 \AA$ resolution (Figure 3, Supplementary Table 1). There are two protein molecules in the asymmetric unit (chains $\mathrm{A} / \mathrm{B}$, Supplementary Figure 1); electron density for both $(S)$ - and $(R)$-enantiomers of $\mathbf{3}$ was apparent in each of the chains. Each enantiomer of $\mathbf{3}$ was refined with $50 \%$ occupancy in both $\mathrm{A}$ and $\mathrm{B}$ chains. 3 was prepared as a mixture in which the $(R)$ - 
enantiomer was in excess as assigned by NMR of intermediates (see above), thus the crystallographic evidence indicates binding of the $(S)$-enantiomer may be preferred, though further work is required to verify this proposal in solution. The electron density for $\mathbf{3}$ in both chains $A$ and $B$ is clearly consistent with the presence of a 'tetrahedral' bicyclic boronate. The general binding mode of the bicyclic boronate core and its carboxylate are very similar to those reported for 2 and related compounds with VIM-2 and other MBLs, including NDM$1^{34}$. No evidence for partial tricyclisation, as observed crystallographically for VNRX-5133 in complex with NDM-1 was observed ${ }^{18}$. These observations further support the use of bicyclic boronic acids/boronates to mimic $\beta$-lactam containing $\beta$-lactamase substrates (in their $s p^{2}$ form) and enzyme bound high energy tetrahedral intermediates (in their $\mathrm{sp}^{3}$ form).

A

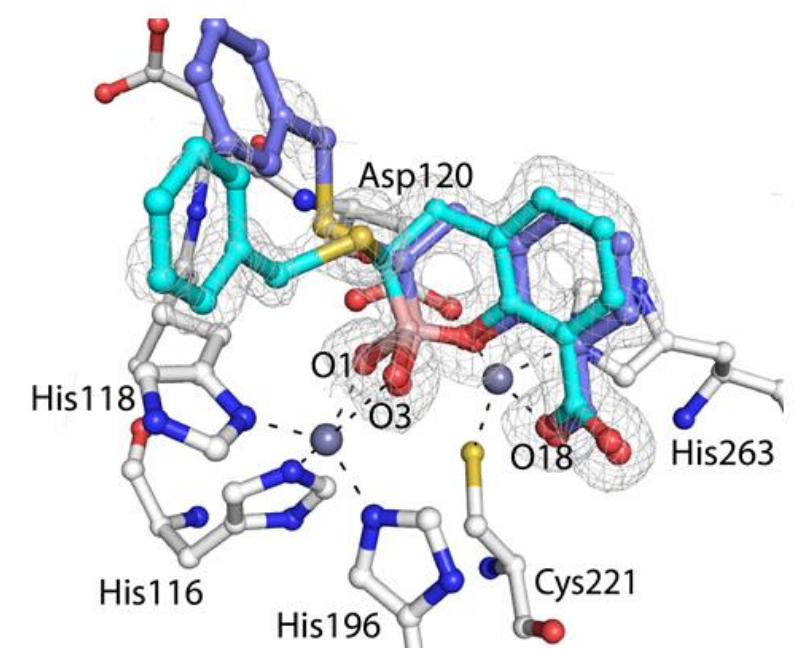

B

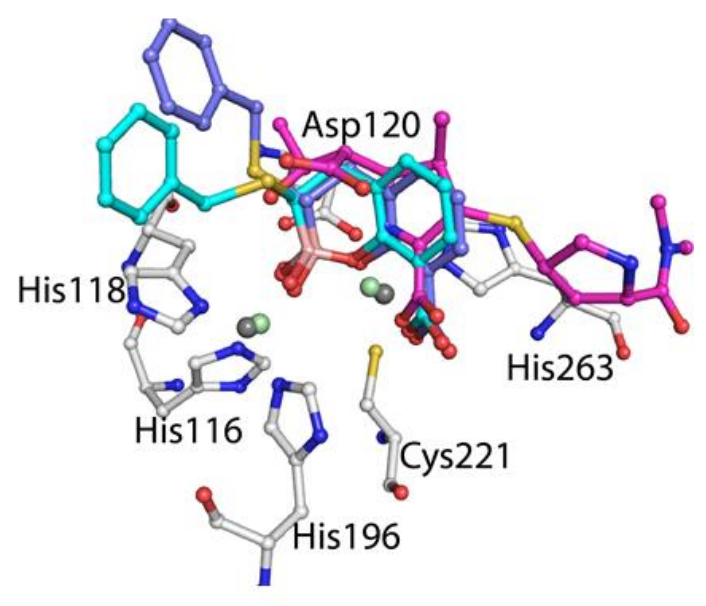

Figure 3. Mode of inhibition of the VIM-2 MBL by thioether 3. (A) View from a crystal structure of the thioether bicyclic boronate 3 in complex with VIM-2. Both the $(R)$ - (cyan) and (S)- (slate blue) enantiomers of $\mathbf{3}$ are present in the active site. $\mathrm{mF}_{\mathrm{o}}-\mathrm{DF}_{\mathrm{c}}$ OMIT electron density contoured to $3 \sigma$ is shown as a grey mesh. Note; the phenyl side-chain of $\mathbf{3}$ is partially disordered in both the $(S)$ - and $(R)$-enantiomers, as reflected by high B-factors for these atoms. (B) Comparison of crystal structures of VIM-1 in complex with hydrolysed meropenem (pink) ${ }^{31}$ along with the $R$-enantiomer(cyan) and the $S$-enantiomer (slate blue) of C-3 thioether 3. The zinc ions for VIM-1 (5N5I) are shown in green and in grey for VIM-2 (6RPN). 
One of the oxygen atoms (HETATM designation O18) of the C-3 carboxylate of 3 is positioned to coordinate to Zn2 of the di-zinc ion active site of VIM-2, as is the 'endocyclic' boronate ring oxygen (Figures 3,4). Moreover, there is clear re-positioning of the zinc ions in the active site when compared to "resting state" VIM-2 structures, with the $\mathrm{Zn}-\mathrm{Zn}$ distance increasing from $\sim 3.5 \AA$ to $4.3 \AA$ (Figure 4 ). ${ }^{27}$ These observations are consistent with other solution and crystallographic studies, implying metal ion movement may occur during inhibition and catalysis by MBLs and other metallo-enzymes. ${ }^{35,36}$

The L3 loop bordering the VIM-2 active site is in a different position compared to the reported unligated structures, apparently to accommodate the binding of 3 (Figure 4). Compared to previously reported structures of VIM-2 with the cyclic boronate $2^{17,20}$, the overall binding position of the bicyclic boronate core rings of $\mathbf{2}$ and $\mathbf{3}$ are very similar; however, 2 binds at a slightly greater distance $(2.5 \AA)$ from the zinc ions compared to 3 (2.3 Å) relative to the boron bound oxygens/hydroxides (Figure 4). Moreover, the non-zinc ionligating carboxylate oxygen of 3 (HETATM designation O19) is positioned to form a hydrogen bond with the amide nitrogen of Asn233 (Figure 5). The 'exocyclic' boron bound oxygens/hydroxides (HETATM designation $\mathrm{O} 3$ and $\mathrm{O} 1$ ) appear to mimic the binding modes proposed for the two oxygens in the oxyanion intermediate in $\beta$-lactam hydrolysis (Figure 3 ). Again, as with 2 and related compounds ${ }^{17,20}$, the bicyclic phenyl-boronate ring of 3 is analogously positioned to the cephalosporin dihydrothiazine ring (or analogous penicillin/carbapenem $\beta$-lactam fused rings) at the VIM-2 active site, i.e. the bicyclic boronates have a similar overall active site binding mode to cephalosporins / other $\beta$-lactam substrates. 

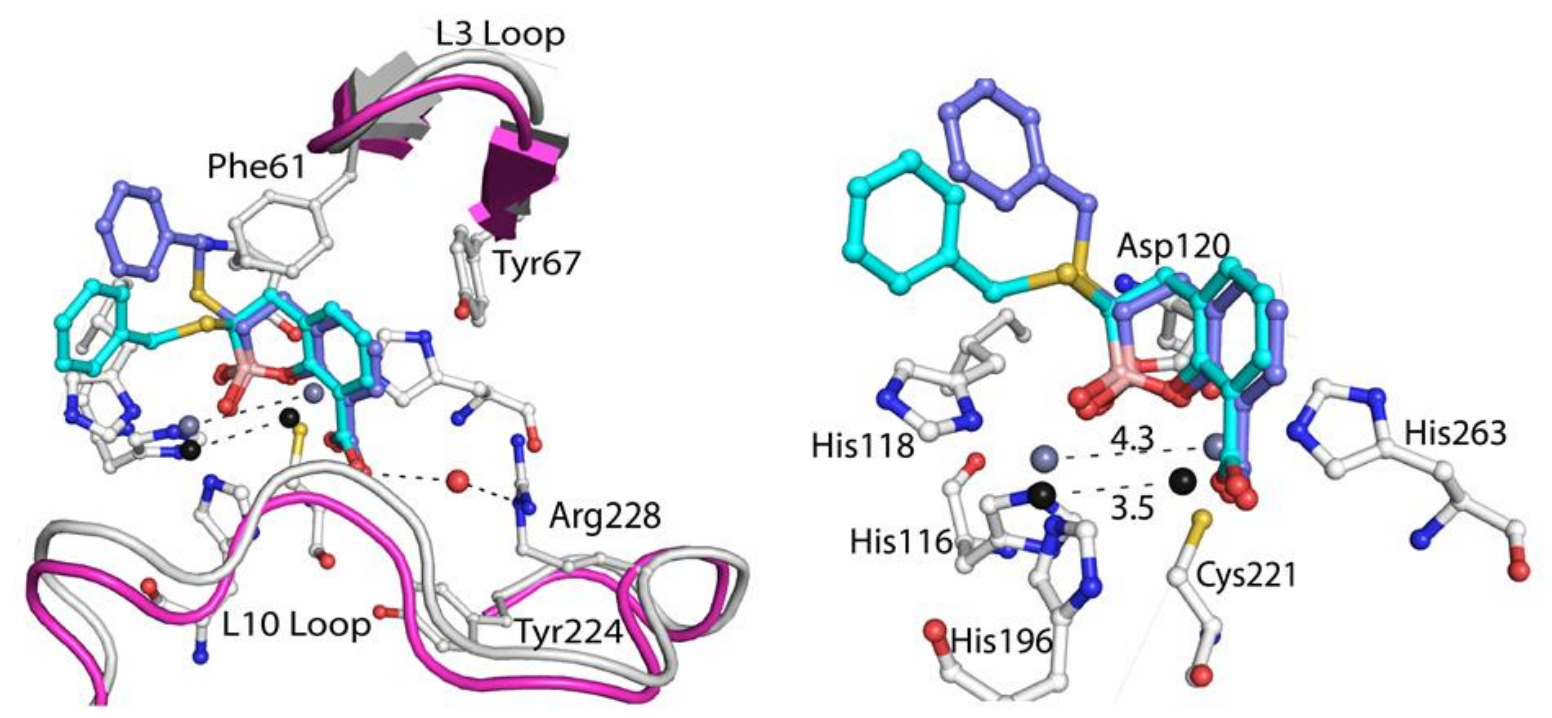

Figure 4. Comparison of the L3 and L10 loop conformations and zinc-zinc distances in the VIM-2 resting state (4BZ3) (pink) and VIM-2 in complex with thioether 3 (white) (6RPN). (A) Both the L3 and L10 loops adopt different positions in the resting state (pink) compared to the complex with 3 (white). Residues important for interactions are also shown. (B) When 3 is bound to VIM-2, the zinc ions are displaced; VIM-2 (black) compared to VIM2:3 complex (grey). Distances are in $\AA$.
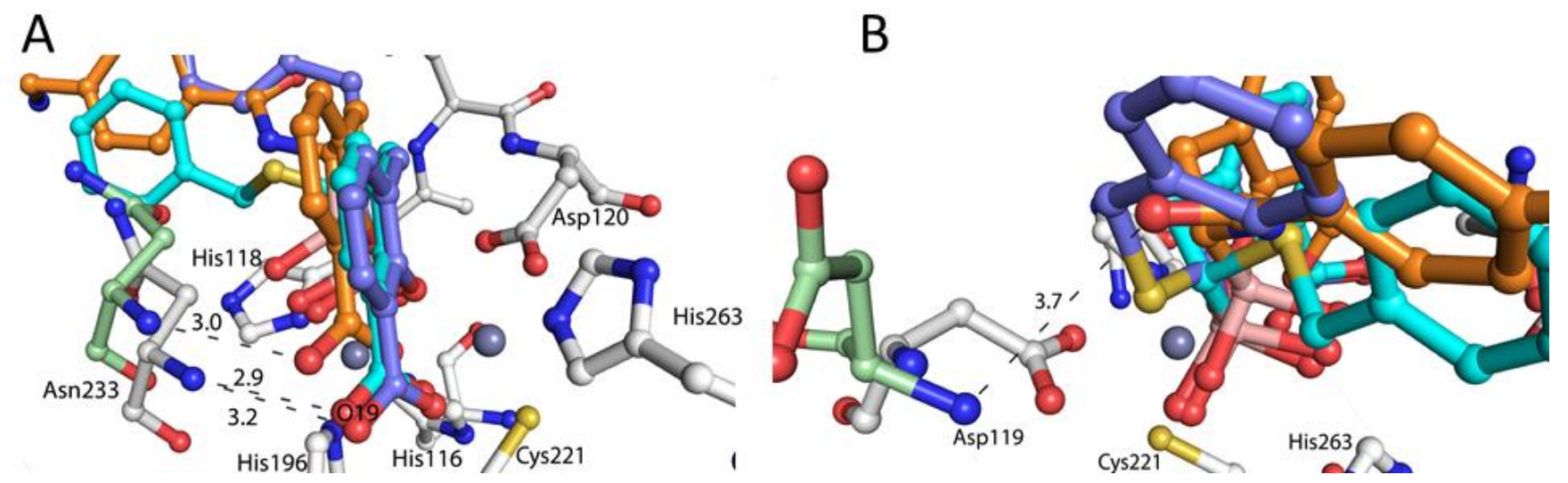

Figure 5. Views from crystal structures of the (S)- and (R)-enantiomers of 3 ((blue and cyan respectively) superimposed with that of 2 (orange) at the VIM2 active site comparing analogous hydrogen bonding interactions. A) One carboxylate oxygen (HETATM O18) of both 2 and 3 interacts with the main chain amide of Asn233. PDB IDs 6RPN and 5FQC. B) The carbonyl group of the acylamino side chain of compound 2 
interacts with the backbone $\mathrm{NH}$ of Asp119; 3 cannot make this interaction due to its thioether sidechain. Residues Asp119 and Asn233 from the VIM-2:2 complex structure are shown in green (PDB: 5FQC) Hydrogen bonds: dotted lines. Distances are in Å.

At the VIM-2 MBL active site, the C-6 thioether side chain of 3 projects in a similar direction to that of the acylamino side chain of cephalosporin derived complexes and that of $\mathbf{2}^{14,17,19,36}$ However, 3 does not have an amido group containing side chain, hence cannot hydrogen bond with the backbone NH of Asp119 as observed for substrates/inhibitors with acylamino(e.g. 2, penicillins, cephalosporins) or hydroxyethyl (carbapenems) sidechains. This difference may, at least in part, reflect variations in the inhibition potencies of 2,3 and VNRX5133 though different sidechain conformations may also be important. It should also be noted that this interaction is not essential for potent inhibition of some $\beta$-lactamases (e.g. AmpC $P$. aeruginosa) and OXA-48, where 3 is more potent than 2, Table 1), though given the mostly lower activity of $\mathbf{3}$ compared to $\mathbf{2}$, it is possible that it can promote binding.

\section{Conclusions}

The combined inhibition, crystallographic and microbiological results support the potential of bicyclic boronate based $\beta$-lactamase inhibitors with broad spectrum activity against both SBLs and MBLs. In principle, bicyclic boronates are in equilibrium with monocyclic and potentially even acyclic forms, which can react with nucleophilic active site residues. ${ }^{39}$ In several cases, structural studies have revealed the potential for enzyme bound boronate esters to undergo unexpected reactions, as exemplified by the observation of tricyclic ring formation in the reaction of the bicyclic boronate VNRX-5133 with NDM-1 and tricovalent binding of a boronate with a penicillin binding protein. ${ }^{18,40}$ However, in most (bi)cyclic cases studied by protein crystallography, the core cyclic unit, as observed in solution, appears to adopt a bicyclic structure as revealed in this study (Figures 3 and 4) and in most previous work as shown in Supplementary Figure 2 which compares the observed binding modes of different bicyclic boronates in both MBLs and SBLs. ${ }^{14,18,19,18}$ 
Although there are limited studies on the various side chain types in bicyclic boronates reported in the academic literature ${ }^{14,19}$ our study indicates that the potency/selectivity of the bicyclic boronates can be substantially altered by the nature of the C-3 substituent (equivalent to C-6 penicillin, C-7 cephalosporin side chains). Thus, whilst 3 was less potent than 2 against some of the tested $\beta$-lactamases, it was more potent against others, notably MBLs in the B2 (CphA) and B3 subclasses (L1), revealing the potential of bicyclic boronates for potent inhibition of all three MBL subclasses. Although 3 is a potent inhibitor of some $\beta$ lactamases, it was not very active in our cell based assays (including compared to 2$)^{14}$, possibly due to lack of cell penetration and/or efflux.

The results overall imply not only that further work on side chain SAR of bicyclic boronates will be productive, but that it may also be useful to revisit side chain chemistry of the established types of $\beta$-lactam containing SBL/transpeptidase inhibitors, the SAR of which mostly reflects cell-based studies. At least in the case of the clinically established $\beta$-lactam based Class A SBL inhibitors, the range of C- 6 penicillin equivalent side chains is limited to either none (e.g. as in clavulanic acid, sulbactam, tazobactam) or hydroxyethyl (carbapenems). The suggestion that further work on side chain optimisation should be done is supported by ongoing work concerning derivatives of avibactam, wherein substitution of the avibactam $\mathrm{CONH}_{2}$ side chain can lead to improved activity, including with respect to conferring transpeptidase inhibition / antibacterial activity. ${ }^{39}$ Given the enormous contemporary societal importance of $\beta$-lactams and related antibiotics, we suggest there is considerable scope for continued work in the field. 


\section{Acknowledgements}

The Trapencieris group thanks the 7th FP project (InnovaBalt) and Latvian Institute of Organic Synthesis internal grant IG-2016-09 and IG-2018-08 for funding. The Schofield group thanks the Wellcome Trust, University of Oxford, the EPSRC and MRC (Grant EP/L016044/1) for funding on $\beta$-lactamases and related enzymes. We thank the staff of Diamond Light Source for technical support.

\section{Supporting Information}

The Supporting information Available: Contains further information about synthesis of compound and crystallographic data processing.

\section{Author Information}

This research was conceived by C. Schofield, P. Trapencierisk, and J. Brem. Synthesis and characterisation was performed by A. Parkova and A. Krajnc and crystallography was done by A. Lucic with help from M. A. McDonough and J. Brem. G. Langley, and K. Calvopina performed the kinetic experiments and microbiology studies respectively. C. Schofield, A. Parkova and A. Lucic drafted the manuscript which was commented on by all authors.

\section{List of Abbreviations}

CLSI: Clinical Laboratory Standards Institute

MBL: Metallo- $\beta$-lactamase

MIC: Minimum Inhibitory Concentrations

NDM-1: New Delhi metallo- $\beta$-lactamase 1

SAR: Structure Activity Relationship

SBL: Serine- $\beta$-lactamases

SPM-1: São Paulo metallo- $\beta$-lactamase 1

VIM-1: Verona Integron metallo- $\beta$-lactamase 1

VIM-2: Verona Integron metallo- $\beta$-lactamase 2 


\section{Conflict of Interest Disclosure}

The authors declare no competing financial interest.

\section{References}

(1) Fair, R. J.; Tor, Y. Antibiotics and Bacterial Resistance in the 21st Century. Perspect. Medicin. Chem. 2014, 6, 25-64.

(2) Frère, J.-M.; Joris, B.; Granier, B.; Matagne, A.; Jacob, F.; Bourguignon-Bellefroid, C. Diversity of the Mechanisms of Resistance to $\beta$-Lactam Antibiotics. Res. Microbiol. 1991, 142 (6), 705-710.

(3) Bush, K.; Jacoby, G. A. Updated Functional Classification of Beta-Lactamases. Antimicrob. Agents Chemother. 2010, 54 (3), 969-976.

(4) Walsh, T. R.; Toleman, M. A.; Poirel, L.; Nordmann, P. Metallo-Beta-Lactamases: The Quiet before the Storm? Clin. Microbiol. Rev. 2005, 18 (2), 306-325.

(5) Struelens marcstruelens, M. J.; Monnet, D. L.; Magiorakos, A. P.; Santos, F. O.; Giesecke, J.; European NDM-, the; Participants, S. New Delhi Metallo-BetaLactamase 1-Producing Enterobacteriaceae: Emergence and Response in Europe; 110, 2010.

(6) Reading, C.; Cole, M. Clavulanic Acid: A Beta-Lactamase-Inhiting Beta-Lactam from Streptomyces Clavuligerus. Antimicrob. Agents Chemother. 1977, 11 (5), 852-857.

(7) Campoli-Richards, D. M.; Brogden, R. N. Sulbactam/Ampicillin. Drugs 1987, 33 (6), 577-609.

(8) Bryson, H. M.; Brogden, R. N. Piperacillin/Tazobactam. Drugs 1994, 47 (3), 506-535.

(9) Weldhagen, G. F. Integrons and $\beta$-Lactamases-a Novel Perspective on Resistance. Int. J. Antimicrob. Agents 2004, 23 (6), 556-562.

(10) Ehmann, D. E.; Jahic', H.; Ross, P. L.; Gu, R.-F.; Hu, J.; Kern, G.; Walkup, G. K.; Fisher, S. L.; Designed, S. L. F.; Performed, G. K. W. Avibactam Is a Covalent, 
Reversible, Non- $\beta$-Lactam $\beta$-Lactamase Inhibitor. PNAS 2012, 109 (29), 11663-

(11) Wang, D. Y.; Abboud, M. I.; Markoulides, M. S.; Brem, J.; Schofield, C. J. The Road to Avibactam: The First Clinically Useful Non- $\beta$-Lactam Working Somewhat like a $\beta$ Lactam. Future Med. Chem. 2016, 8 (10), 1063-1084.

(12) Abboud, M. I.; Damblon, C.; Brem, J.; Smargiasso, N.; Mercuri, P.; Gilbert, B.; Rydzik, A. M.; Claridge, T. D. W.; Schofield, C. J.; Frère, J.-M. Interaction of Avibactam with Class B Metallo- $\beta$-Lactamases. Antimicrob. Agents Chemother. 2016, 60 (10), 56555662.

(13) Diaz, D. B.; Yudin, A. K. The Versatility of Boron in Biological Target Engagement. Nat. Chem. 2017, 9 (8), 731-742.

(14) Cahill, S. T.; Cain, R.; Wang, D. Y.; Lohans, C. T.; Wareham, D. W.; Oswin, H. P.; Mohammed, J.; Spencer, J.; Fishwick, C. W. G.; McDonough, M. A.; et al. Cyclic Boronates Inhibit All Classes of $\beta$-Lactamases. Antimicrob. Agents Chemother. 2017, $61(4), 1-13$,

(15) Woon, E. C. Y.; Zervosen, A.; Sauvage, E.; Simmons, K. J.; Živec, M.; Inglis, S. R.; Fishwick, C. W. G.; Gobec, S.; Charlier, P.; Luxen, A.; et al. Structure Guided Development of Potent Reversibly Binding Penicillin Binding Protein Inhibitors. ACS Med. Chem. Lett. 2011, 2 (3), 219-223.

(16) Zhanel, G. G.; Lawrence, C. K.; Adam, H.; Schweizer, F.; Zelenitsky, S.; Zhanel, M.; Lagacé-Wiens, P. R. S.; Walkty, A.; Denisuik, A.; Golden, A.; et al. ImipenemRelebactam and Meropenem-Vaborbactam: Two Novel Carbapenem- $\beta$-Lactamase Inhibitor Combinations. Drugs 2018, 78 (1), 65-98.

(17) Cahill, S. T.; Tyrrell, J. M.; Navratilova, I. H.; Calvopiña, K.; Robinson, S. W.; Lohans, C. T.; McDonough, M. A.; Cain, R.; Fishwick, C. W. G.; Avison, M. B.; et al. Studies on the Inhibition of AmpC and Other $\beta$-Lactamases by Cyclic Boronates. Biochim. Biophys. Acta - Gen. Subj. 2019, 1863 (4), 742-748.

(18) Krajnc, A.; Brem, J.; Hinchliffe, P.; Calvopiña, K.; Panduwawala, T. D.; Lang, P. A.; Kamps, J. J. A. G.; Tyrrell, J. M.; Widlake, E.; Saward, B. G.; et al. Bicyclic Boronate 
VNRX-5133 Inhibits Metallo- and Serine- $\beta$-Lactamases. J. Med. Chem. 2019, 62 (18), 8544-8556.

(19) Liu, B.; E. Lee Trout, R.; Chu, G.-H.; McGarry, D.; W Jackson, R.; Hamrick, J.; Daigle, D.; Cusick, S.; Pozzi, C.; De Luca, F.; et al. Discovery of Taniborbactam (VNRX5133): A Broad-Spectrum Serine- and Metallo- $\beta$-Lactamase Inhibitor for CarbapenemResistant Bacterial Infections. J. Med. Chem. 2019, 1-60.

(20) Brem, J.; Cain, R.; Cahill, S.; McDonough, M. A.; Clifton, I. J.; Jiménez-Castellanos, J.-C.; Avison, M. B.; Spencer, J.; Fishwick, C. W. G.; Schofield, C. J. Structural Basis of Metallo- $\beta$-Lactamase, Serine- $\beta$-Lactamase and Penicillin-Binding Protein Inhibition by Cyclic Boronates. Nat. Commun. 2016, 7, 12406, 1-8,

(21) Buynak, J. D. $\beta$-Lactamase Inhibitors: A Review of the Patent Literature (2010 2013). Expert Opin. Ther. Pat. 2013, 23 (11), 1469-1481.

https://doi.org/10.1517/13543776.2013.831071.

(22) Matteson, D. S. Boronic Esters in Asymmetric Synthesis. J. Org. Chem. 2013, 78 (20), 10009-10023.

(23) Matteson, D. S.; Majumdar, D. Homologation of Boronic Esters to .Alpha.-Chloro Boronic Esters. Organometallics 1983, 2 (11), 1529-1535.

(24) Matteson, D. S.; Ray, R. Directed Chiral Synthesis with Pinanediol Boronic Esters. J. Am. Chem. Soc. 1980, 102 (25), 7590-7591.

(25) Langley, G. W.; Cain, R.; Tyrrell, J. M.; Hinchliffe, P.; Calvopiña, K.; Tooke, C. L.; Widlake, E.; Dowson, C. G.; Spencer, J.; Walsh, T. R.; et al. Profiling Interactions of Vaborbactam with Metallo- $\beta$-Lactamases. Bioorg. Med. Chem. Lett. 2019, 29 (15), 1981-1984.

(26) van Berkel, S. S.; Brem, J.; Rydzik, A. M.; Salimraj, R.; Cain, R.; Verma, A.; Owens, R. J.; Fishwick, C. W. G.; Spencer, J.; Schofield, C. J. Assay Platform for Clinically Relevant Metallo- $\beta$-Lactamases. J. Med. Chem. 2013, 56 (17), 6945-6953.

(27) Brem, J.; van Berkel, S. S.; Zollman, D.; Lee, S. Y.; Gileadi, O.; McHugh, P. J.; Walsh, T. R.; McDonough, M. A.; Schofield, C. J. Structural Basis of Metallo- $\beta$-Lactamase 
Inhibition by Captopril Stereoisomers. Antimicrob. Agents Chemother. 2016, 60 (1), $142-150$.

(28) Golemi, D.; Maveyraud, L.; Vakulenko, S.; Samama, J. P.; Mobashery, S. Critical Involvement of a Carbamylated Lysine in Catalytic Function of Class D BetaLactamases. Proc. Natl. Acad. Sci. U. S. A. 2001, 98 (25), 14280-14285.

(29) Verma, V.; Testero, S. A.; Amini, K.; Wei, W.; Liu, J.; Balachandran, N.; Monoharan, T.; Stynes, S.; Kotra, L. P.; Golemi-Kotra, D. Hydrolytic Mechanism of OXA-58 Enzyme, a Carbapenem-Hydrolyzing Class D $\beta$-Lactamase from Acinetobacter Baumannii. J. Biol. Chem. 2011, 286 (43), 37292-37303.

(30) van Groesen, E.; Lohans, C. T.; Brem, J.; Aertker, K. M.; Claridge, T. D.; Schofield, C. 19F-NMR Monitoring of Reversible Protein Post-Translational Modifications: Class D B-Lactamase Carbamylation and Inhibition. Chem. - A Eur. J. 2019, chem, 1183711841.201902529.

(31) Salimraj, R.; Hinchliffe, P.; Kosmopoulou, M.; Tyrrell, J. M.; Brem, J.; van Berkel, S. S.; Verma, A.; Owens, R. J.; McDonough, M. A.; Walsh, T. R.; et al. Crystal Structures of VIM-1 Complexes Explain Active Site Heterogeneity in VIM-Class Metallo- $\beta$ Lactamases. FEBS J. 2019, 286 (1), 169-183.

(32) M100 Performance Standards for Antimicrobial Susceptibility Testing An Informational Supplement for Global Application Developed through the Clinical and Laboratory Standards Institute Consensus Process.

(33) Lomovskaya, O.; Sun, D.; Rubio-Aparicio, D.; Nelson, K.; Tsivkovski, R.; Griffith, D. C.; Dudley, M. N. Vaborbactam: Spectrum of Beta-Lactamase Inhibition and Impact of Resistance Mechanisms on Activity in Enterobacteriaceae. Antimicrob. Agents Chemother. 2017, 61 (11), e01443-17.

(34) King, D. T.; Worrall, L. J.; Gruninger, R.; Strynadka, N. C. J. New Delhi Metallo- $\beta-$ Lactamase: Structural Insights into $\beta$-Lactam Recognition and Inhibition. J. Am. Chem. Soc. 2012, 134 (28), 11362-11365.

(35) Strynadka, N. C. J.; Martin, R.; Jensen, S. E.; Gold, M.; Jones, J. B. Structure-Based 
Design of a Potent Transition State Analogue for TEM-1 $\beta$-Lactamase. Nat. Struct. Mol. Biol. 1996, 3 (8), 688-695.

(36) Rojas, L. J.; Taracila, M. A.; Papp-Wallace, K. M.; Bethel, C. R.; Caselli, E.; Romagnoli, C.; Winkler, M. L.; Spellberg, B.; Prati, F.; Bonomo, R. A. Boronic Acid Transition State Inhibitors Active against KPC and Other Class A $\beta$-Lactamases: Structure-Activity Relationships as a Guide to Inhibitor Design. Antimicrob. Agents Chemother. 2016, 60 (3), 1751-1759.

(37) Raczynska, J. E.; Shabalin, I. G.; Minor, W.; Wlodawer, A.; Jaskolski, M. A Close Look onto Structural Models and Primary Ligands of Metallo- $\beta$-Lactamases. Drug Resist. Updat. 2018, 40, 1-12.

(38) Krajnc, A.; Lang, P. A.; Panduwawala, T. D.; Brem, J.; Schofield, C. J. Will Morphing Boron-Based Inhibitors Beat the $\beta$-Lactamases? Curr. Opin. Chem. Biol. 2019, 50, $101-110$.

(39) Dzhekieva, L.; Adediran, S. A.; Pratt, R. F. Interactions of \&quot;BoraPenicilloates\&quot; with Serine $\beta$-Lactamases and DD-Peptidases. 2014, 6530-6538.

(40) Zervosen, A.; Herman, R.; Kerff, F.; Herman, A.; Bouillez, A.; Prati, F.; Pratt, R. F.; Frère, J.-M.; Joris, B.; Luxen, A.; et al. Unexpected Tricovalent Binding Mode of Boronic Acids within the Active Site of a Penicillin-Binding Protein. J. Am. Chem. Soc. 2011, 133 (28), 10839-10848. 


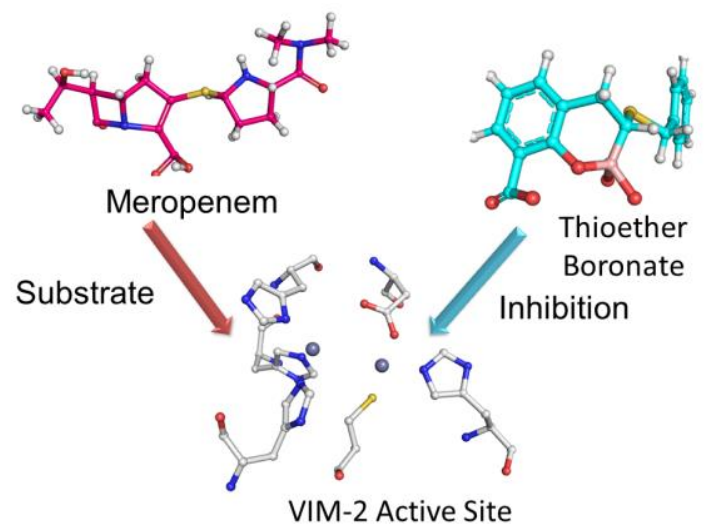

For Table of Contents Only: Serine and metallo- $\beta$-lactamases are inhibited by a bicyclic boronate with a thioether sidechain. 